\title{
8
}
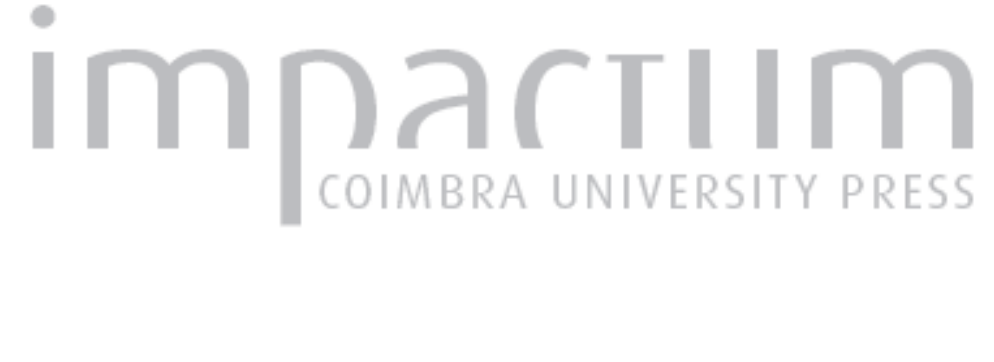

\section{O imaginário colonial português na revista antena (1965-1968) do rádio clube português}

\author{
Autor(es): Henriques, Cláudia
}

Publicado por: Imprensa da Universidade de Coimbra

URL persistente:

URI:http://hdl.handle.net/10316.2/39635

DOI:

DOI:http://dx.doi.org/10.14195/2183-5462_29_9

Accessed : $\quad$ 26-Apr-2023 10:50:16

A navegação consulta e descarregamento dos títulos inseridos nas Bibliotecas Digitais UC Digitalis, UC Pombalina e UC Impactum, pressupõem a aceitação plena e sem reservas dos Termos e Condições de Uso destas Bibliotecas Digitais, disponíveis em https://digitalis.uc.pt/pt-pt/termos.

Conforme exposto nos referidos Termos e Condições de Uso, o descarregamento de títulos de acesso restrito requer uma licença válida de autorização devendo o utilizador aceder ao(s) documento(s) a partir de um endereço de IP da instituição detentora da supramencionada licença.

Ao utilizador é apenas permitido o descarregamento para uso pessoal, pelo que o emprego do(s) título(s) descarregado(s) para outro fim, designadamente comercial, carece de autorização do respetivo autor ou editor da obra.

Na medida em que todas as obras da UC Digitalis se encontram protegidas pelo Código do Direito de Autor e Direitos Conexos e demais legislação aplicável, toda a cópia, parcial ou total, deste documento, nos casos em que é legalmente admitida, deverá conter ou fazer-se acompanhar por este aviso.

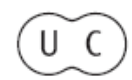




\section{Media Jornalismo}

\section{MÉDIA E COLONIALISMO(S)}




\title{
O IMAGINÁRIO COLONIAL PORTUGUÊS NA REVISTA ANTENA (1965-1968) DO RÁDIO CLUBE PORTUGUÊS
}

\section{THE PORTUGUESE COLONIAL IMAGINARY IN THE MAGAZINE ANTENA (1965-1968) OF THE PORTUGUESE RADIO CLUB}

\author{
CLÁUDIA HENRIQUES \\ UNIVERSIDADE NOVA DE LISBOA, FACULDADE DE CIÊNCIAS SOCIAIS E HUMANAS, \\ PROGRAMA DE DOUTORAMENTO EM CIÊNCIAS DA COMUNICAÇÃO, CIC.DIGITAL \\ 1069-061 LISB0A, PORTUGAL \\ CLAUDIA.HENRIQUES@SAPO.PT
}

Resumo

A Antena, revista do Rádio Clube Português (RCP), coincide no tempo com o desenrolar da guerra colonial. Entre 1965 e 1968, a revista Antena é, essencialmente, palco das histórias pessoais e profissionais das "estrelas" da música, teatro e cinema da época. Ainda assim, perpassam alguns ecos das situações de conflito em África. A partir da análise de todos os números da Antena, este artigo procura indagar que imaginário colonial é transmitido pela revista, sobretudo no que respeita aos conflitos nas três frentes africanas. Destacamos também as transformações vividas pelo RCP nesta década, tanto ao nível técnico como no campo da programação, e da emergência de um jornalismo radiofónico que tende para a afirmação de uma linguagem e identidade próprias.

\section{Palavras-chave}

Rádio Clube Português; Revista Antena; Imaginário Colonial; Guerra Colonial; Jornalismo Radiofónico; Anos 60

\section{Abstract}

Antena, a magazine owned by the radio station Rádio Clube Português(RCP), coincides in time with the development of the Portuguese colonial war. Between 1965 and 1968, Antena is essentially a stage for the personal and professional stories of the music, theatre and cinema "stars" of the time. Still, some echoes of the conflicts in Africa seeped in. Starting from an analysis of all the issues of Antena, this article seeks to investigate which colonial imaginary is transmitted by the magazine, particularly with regard to conflicts in the three African fronts. We also highlight the changes experienced by the RCP station in this decade, both at the technical level and in the field of programming, as well as the emergence of a radio journalism that tends to affirm its own language and identity.

KEY WORDS

Rádio Clube Português; Antena Magazine; Colonial Imaginary; Colonial War; Radio Journalism; 60's 
A Antena, revista de actualidades do Rádio Clube Português (RCP), coincide no tempo com o desenrolar da guerra colonial nos teatros de operações africanos. Entre 1965 e 1968, a Antena é palco das histórias pessoais e profissionais de "estrelas" da música, teatro e cinema da época. É também o lugar privilegiado para a promoção das figuras e dos programas do RCP. Os grandes acontecimentos nacionais ocupam, nesta publicação, um espaço secundário, enquadrados pela ideologia do Estado Novo e ao serviço dos propósitos de propaganda da estação. É nesta dinâmica de parca e controlada informação que perpassam alguns ecos da vida quotidiana e das situações de conflito em África.

Este estudo analisa o imaginário colonial transmitido pela revista do RCP nos anos 1960, sobretudo no que respeita às três frentes do conflito. Numa perspectiva mais ampla, enquadra-se no contexto das transformações vividas pelo RCP naquela década, tanto ao nível técnico como no campo da programação e da emergência de um jornalismo radiofónico que tende para a afirmação de uma identidade própria.

A partir de uma leitura crítica, da análise quantitativa e qualitativa baseada na revista Antena, e das entrevistas por nós realizadas a jornalistas que exerceram funções no RCP, procuraremos responder a algumas questões: a Antena reflecte a realidade colonial portuguesa, designadamente a guerra? De que forma? Qual o papel do jornalismo radiofónico do RCP, se expresso na revista, na construção do imaginário colonial?

\section{0 RCP NOS ANOS 1960}

\subsection{Uma década "Sempre no Ar, Sempre Consigo"}

Quando a revista Antena é lançada, a rádio em Portugal está a viver um tempo de mudanças. A década de 1960 é o momento cronológico e sócio-político que, em muitos aspectos, representa a ruptura com a rádio tradicional, reverencial, oficial e oficiosa, que se limita a ser caixa de ressonância do regime, e entretém inofensivo. A Emissora Nacional (EN) é disso paradigma. Paralelamente, aparecerão novos profissionais, uma linguagem menos formal e mais próxima do ouvinte, uma relação com a "rua" mais dinâmica, uma atitude de esclarecimento da opinião pública, mudanças técnicas que potenciarão outras experiências radiofónicas, e novas propostas estéticas, tanto para a programação como para a informação. Dina Cristo chama-lhe "a rádio nova" (2005: 26), pelo contraste notório com a rádio fechada em si, que se faz na cabina e dela não sai.

0 RCP dos anos 1960 enquadra-se neste conceito de "rádio nova". É em 1960 que a estação procede à mudança geográfica das instalações da Parede para a Rua Sampaio e Pina, em Lisboa. A partir de 1963 é introduzida a FM (frequência modulada), com maior qualidade sonora na propagação e programação autónoma face às ondas médias. É ainda neste ano que o RCP, no emissor da Parede, passa a emitir 24 horas diárias. A continuidade non-stop da emissão e 0 estreitamento da relação com os ouvintes deram origem a um slogan: "Sempre no Ar, Sempre Consigo" (Santos, 2014: 115-129).

A criação de um Serviço de Noticiários, enquanto estrutura orgânica dentro do RCP, com um espaço físico próprio, com um coordenador a quem foram dados poderes de definição do serviço, da estrutura e estilo dos noticiários, e com uma equipa de trabaIho que lhe era exclusiva está intimamente ligada a estes novos ventos radiofónicos. 
Figura 1 - Destaque em capa a uma das reportagens de João Paulo Guerra (ANTENA N. $\left.{ }^{\circ} 66,1 / 12 / 1967\right)$

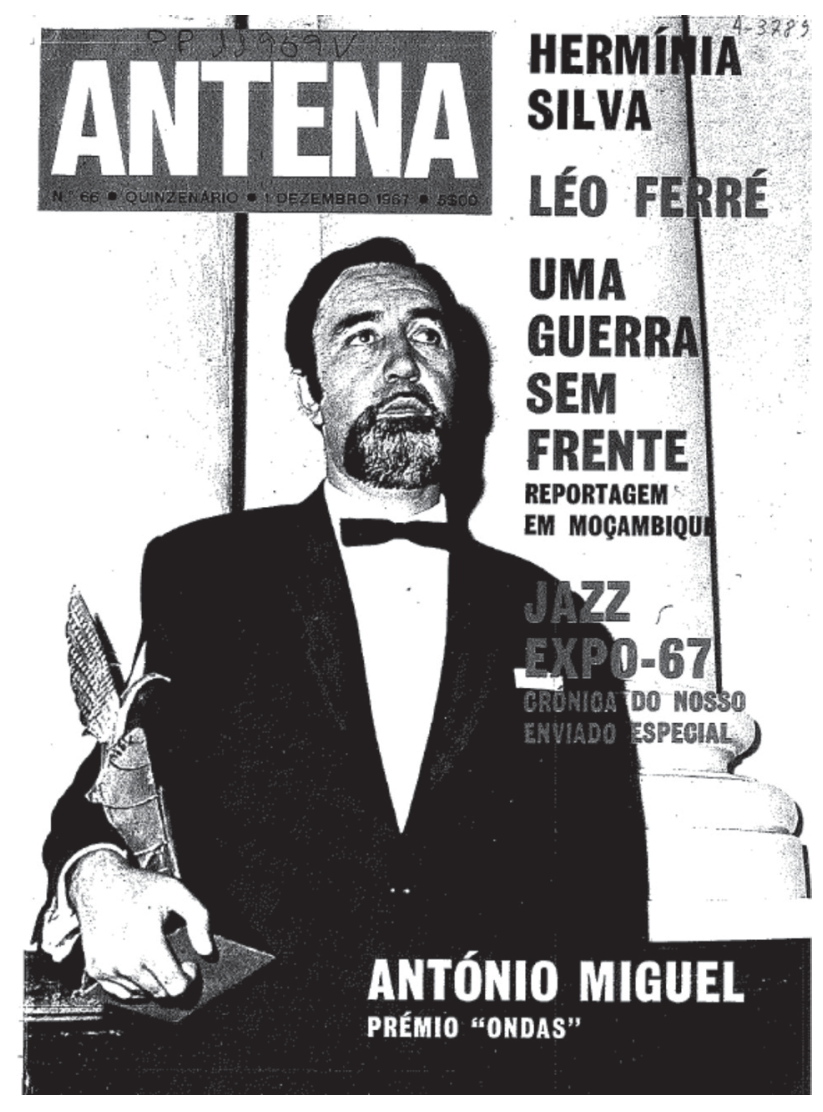

1.2. 0 Serviço de Noticiários: da informação ao jornalismo radiofónico

Os anos 1960, ainda que em contexto de ditadura e censura, trouxeram espessura ao jornalismo em Portugal (Cabrera, 2006; Correia \& Baptista, 2007), possibilitando outras formas de o pensar, novas dinâmicas de recomposição das redacções, do perfil dos seus actores e das suas práticas, naquilo a que Carla Baptista, referindo-se especificamente à imprensa, classificou de "um sopro de renovação do jornalismo" (2012: 206).

Apesar de a história do jornalismo radiofónico português apresentar lacunas que a bibliografia existente ainda não preenche totalmente, os contributos de autores sobre o jornalismo em contexto de rádio nos anos 1960-1970 (Cristo, 2005; Bonixe, 2009; Santos, 2014), permitem-nos aferir que também na informação em rádio foram operadas mudanças de estilo e de conteúdo, designadamente pelos noticiários do RCP.

Rompendo com o modelo cristalizado da informação radiofónica da EN, assente em notícias lidas ao microfone, depois de seleccionadas, recortadas e coladas, provenientes da imprensa e das estruturas de poder oficiais, o Serviço de Noticiários do RCP estabelece uma nova estrutura de apresentação, de narrativa e de adaptação da notícia ao ambiente sonoro. Este projecto jornalístico, segundo Dina Cristo, "constituiria uma 
profunda transformação da concepção informativa radiofónica" em Portugal (2005: 36).

Em 1960 é da cúpula do RCP, por iniciativa de Júlio Botelho Moniz, presidente do Conselho de Administração, que Luís Filipe Costa é chamado a criar um serviço noticioso. 0 propósito era que "fosse diferente dos noticiários maçadores da Emissora Nacional, religiosamente à hora do almoço, durante uma eternidade, feitos de textos pastosos lidos ao microfone" ${ }^{1}$, e que também permitisse obter "dividendos comerciais com publicidade a ser emitida antes e depois da transmissão dos noticiários" ${ }^{2}$.

Com 17 noticiários por dia ${ }^{3}$, de curta duração - não mais de três minutos -, numa cadência informativa quase horária, inédita em Portugal, Filipe Costa tinha na sua equipa informativa cerca de dez profissionais, organizados por turnos, prática comum e identitária da continuidade informativa em rádio (Bonixe, 2012: 91). Também os noticiários cumpriam o lema da estação: Sempre no Ar, Sempre Consigo.

Pelos noticiários do RCP, ao longo dos anos 1960-1970, para além de Luís Filipe Costa, passaram profissionais como Adelino Gomes, João Paulo Guerra, Joaquim Letria, Manuel Bravo ou Paulo Fernando. Estes jornalistas, habitualmente designa-

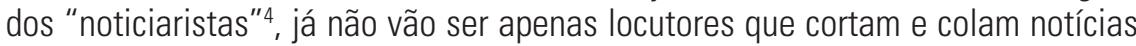
da imprensa do dia anterior; são fazedores, eles próprios, dos textos transmitidos aos ouvintes (Cristo, 2005:35; Santos, 2014:189).

Progressivamente, a informação radiofónica vai-se libertando do peso formal dos textos escritos e chama a si frases curtas e sintéticas. As notícias agilizam-se, e ao microfone ultrapassam-se formas reverenciais de mencionar os cargos. Desenha-se uma outra hierarquia noticiosa, aproximada ao conceito de valores-notícia, que deitará por terra a velha hierarquia de acontecimentos ditada pelas figuras do Estado Novo e pela sua ordem de importância (Cristo, 2005: 33-40; Santos, 2014: 186-190).

\section{Antena: uma revista ao serviço do Rádio Clube Português}

0 primeiro número da revista Antena surge a 1 de Março de 1965 e 0 último data de 15 de Outubro de 1968. Propriedade do RCP, esta publicação quinzenal tinha por director Botelho Moniz, e por editor Fernando Peres. É uma revista de médio formato, cujo número de páginas oscilou, ao longo dos anos, entre as 48 e as 74 páginas a preto e branco, com capas a cores. Em Novembro de 1968, a revista Antena funde-se com a revista $T V$, dando lugar a uma nova publicação - a Nova Antena-, fruto da sociedade entre o RCP, a Rádio Renascença (RR), e a Rádio Televisão Portuguesa (RTP).

No texto de apresentação, Júlio Botelho Moniz atribui à revista o objectivo e a faculdade de "concretizar, através da palavra escrita, aquilo que muitos ouvintes não se apercebem no decorrer das nossas emissões" ${ }^{5}$. E é também nesse texto primeiro da Antena que as palavras "jornalismo" e "jornalistas" aparecem nítidas:

1 Entrevista dada por João Paulo Guerra à autora em 7 de Maio de 2014.

2 Entrevista dada por Luís Filipe Costa à autora em 20 de Outubro de 2014.

3 Cristo apud Rádio \& Televisão, 09/08/1969, p. 33.

4 Até 1975, os jornalistas da rádio não dispunham de carteira-profissional de jornalista nem pertenciam ao Sindicato dos Jornalistas. Até alcançarem esse estatuto, estes profissionais eram designados "noticiaristas" e/ ou "redactores-locutores".

5 Antena, n. ${ }^{0} 1,01 / 03 / 1965$, p. 1. 
Assim como jornalistas vieram para a Rádio, em muito boa hora, acrescente-se, e nela são queridos e respeitados, surgem agora no jornalismo algumas pessoas que, até há pouco, o público conhecia apenas pela voz. ${ }^{6}$

Pelas palavras da figura tutelar da estação quase podemos pressentir que está a nascer uma revista com matizes sonoros, que trará palco a jornalistas que só tardiamente, relativamente a outros media - 0 texto é clarificador desse descompasso -, chegaram ao dispositivo radiofónico. Mas a leitura crítica da revista aponta para outros alvos mediáticos. São publicados 87 números e 5504 páginas ${ }^{7}$, dedicada, essencialmente, a actores e cantores, nacionais e estrangeiros, daquela época. "É o tempo dos grandes astros", diz Adelino Gomes, "e não havendo revistas do coração como actualmente, estas revistas leves de actores e espectáculos entretinham as pessoas"8.

Logo no primeiro número, a fotografia de uma jovem Simone de Oliveira e a imagem de uma antena emissora de rádio parecem dar o tom sobre o que o RCP almejava com a publicação: publicitar e promover a rádio, sim, mas numa lógica de proximidade preferencial com o entretenimento. É uma revista de "estrelas", por onde desfilam Raquel Welsh, Madalena Iglésias, Rita Pavone, Tony de Matos ou Charles Aznavour.

Não há lugar na revista para os grandes acontecimentos nacionais, como Rogério Santos sublinha. Nesta leitura plácida que a Antena proporciona, de capas coloridas e apelativas, com os "famosos" do momento como objecto principal, sempre sorridentes e bem-sucedidos, "é quase impossível descortinar as mudanças sociais, culturais e políticas que se operavam lentamente no país". (Santos, 2012: 257)

Para além das histórias das "estrelas" da música, teatro e cinema, a revista apostava em artigos sobre as figuras e os programas do RCP ("Talismã", "Em Órbita", "Meia Noite", "Sintonia 63"), promovendo-os, e na apresentação de uma grelha com os programas da estação. A Antena incluía também rubricas ou colunas fixas sobre vários assuntos, com destaque para conselhos femininos ("Agora e Sempre a MuIher", de Carlota Álvares Guerra), culinária, tauromaquia, futebol ("Bancada Central", de António Miguel), astrologia, transformações técnicas na rádio (Manuel Meneses), teatro (Fernando Curado Ribeiro), e música e programação de rádio (Matos Maia).

Os editoriais, da responsabilidade de Silva Pinto ou Fernando Peres, assim como os textos acesos de Diamantino Faria, são a marca ideológica mais visível em toda a revista, ao acrescentarem ao entretenimento leve a afirmação patriótica do RCP, "sempre dirigido aos mais altos interesses de Portugal"9. 0 RCP está acima de todas as emissoras, e é a rádio "no caminho certo, o único caminho considerado válido e digno da consciência e da independência dos homens que o dirigem: sempre ao serviço do público e do país."

Recuperando as palavras de Adelino Gomes, e tomando-as como ponto prévio: "que não hajam dúvidas, a Antena era uma revista de eminente propaganda!"11

6 Idem.

7 Antena, n. ${ }^{0} 87$, 15/10/1968, p. 16.

8 Entrevista dada por Adelino Gomes à autora em 19 de Junho de 2015.

9 Antena, n. ${ }^{\circ} 8,15 / 06 / 1965$, p. 1.

10 Antena, n. ${ }^{\circ}$ 5, 01/05/1965, p. 1.

11 Entrevista dada por Adelino Gomes à autora em 19 de Junho de 2015. 
Figura 2 - Uma das reportagens (folha de rosto) de João Paulo Guerra em Moçambique. (ANTENA N. $\left.{ }^{\circ} 65,15 / 11 / 1967\right)$

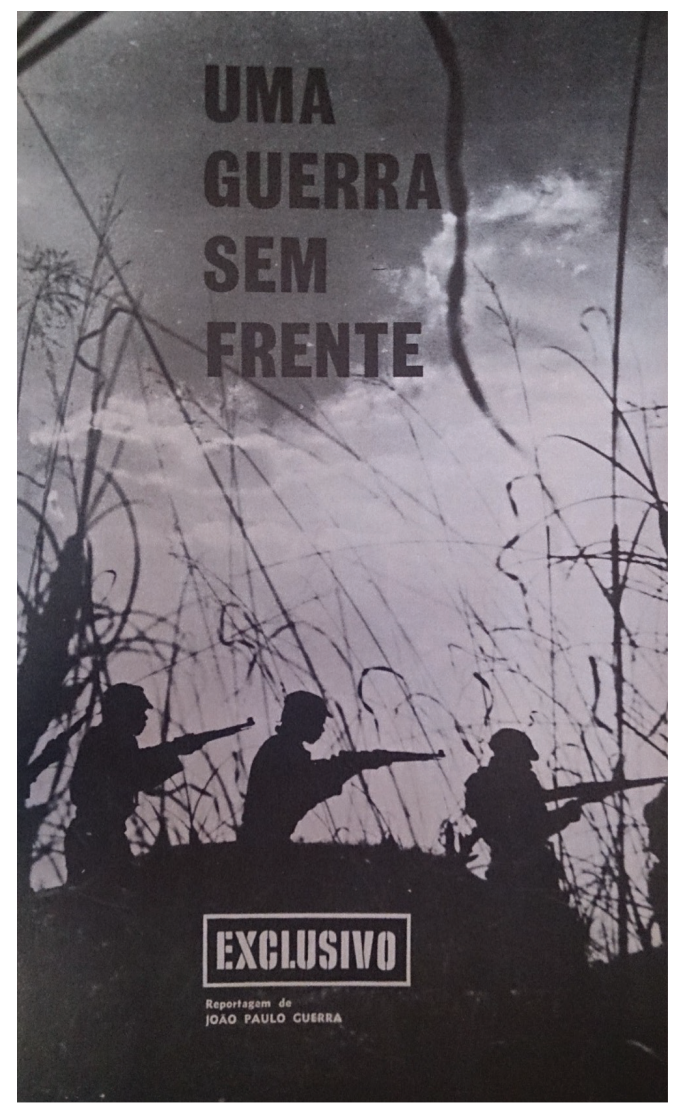

3. 0 universo colonial na Antena: alguns dados quantitativos

A nossa amostra compreende os 87 números publicados da Antena. Estabelecido o corpus, definimos um quadro sumário de categorias de análise, de modo a enquadrar os artigos que se referissem expressamente ao universo colonial, a saber: preponderância dos artigos sobre a questão colonial face à totalidade dos artigos; dimensão dos artigos; distribuição dos artigos por anos; autoria; temas; incidência geográfica dos temas tratados; predominância da imagem; capas que abordem a questão colonial.

No período analisado identificámos 18 revistas que abordam a questão colonial, o que representa um quinto do nosso universo. Numa leitura dos dados relativos ao número de páginas consagradas a esta temática, verificámos que menos de $1 \%$ do total de páginas das 87 edições da Antena aborda a realidade colonial. No entanto, cada artigo referente a esta temática tem em média duas páginas, havendo uma reportagem que atinge as cinco páginas. É, aliás, o elevado número de reportagens (40\%) que explica o maior número de páginas dedicadas ao assunto.

Do cruzamento destes indicadores resulta um quase paradoxo: 0 tema é abordado de forma esporádica, globalmente é ínfimo o espaço em revista que the é 
dedicado, porém os poucos artigos que existem têm alguma dimensão, fruto da escolha da reportagem como texto jornalístico que, de uma forma geral, dá profundidade aos temas que aborda.

Os artigos analisados distribuem-se de forma irregular ao longo dos quatro anos da publicação. Os anos de 1966 e 1968 são aqueles em que a Antena mais aborda as questões relacionadas com 0 universo colonial. 0 ano de 1966 coincide com 0 serviço militar prestado por dois funcionários do RCP que, estando em Angola, produzem quatro reportagens em contexto de guerra. 0 último ano da revista, 1968, é o que tem mais expressão, devido às visitas de Américo Tomás a Cabo Verde e Guiné, bem como ao acompanhamento que a revista faz de um concurso internacional, cujo vencedor em Portugal foi uma criança angolana.

Mais de metade dos artigos em análise não têm autoria identificada, o que se prende com o facto dos artigos e notícias da revista não serem geralmente assinados, exceptuando as colunas, rubricas fixas e algumas entrevistas. São, no entanto, vários (40\%) os artigos assinados, muito devido às reportagens que três funcionários do RCP - dois noticiaristas e um técnico - fizeram em Angola e Moçambique, onde cumpriram serviço militar. Todas as reportagens foram assinadas e destacadas como "exclusivos" da revista.

Neste estudo considerámos as seguintes categorias de temas: guerra colonial; viagens presidenciais às "colónias"; perspectivas sobre o "colonizado"; a rádio nas "colónias", e práticas radiofónicas relacionadas com a questão colonial. Os artigos que têm maior recorrência na Antena são os que se debruçam sobre a guerra colonial, fruto das reportagens que já referimos. Logo a seguir destacam-se os artigos que abordam a prática radiofónica em Angola, por via da perspectiva do entretenimento, uma vez que a revista do RCP estava orientada para os artistas e espectáculos. Seguem-se depois as notícias sobre as viagens presidenciais a Cabo Verde e à Guiné, em 1968, bem como aos artigos que nos oferecem, essencialmente, a perspectiva da revista sobre os povos colonizados. Entra nesta categoria temática os vários artigos feitos sobre José Chimunga, a criança angolana que, em 1968, ganhou o concurso "Operação Plus Ultra".

Em termos geográficos, Angola lidera na atenção que a revista tem sobre o universo colonial. Seguem-se a Guiné e Cabo Verde, devido às notícias referentes às visitas de Américo Tomás. E, por fim, a situação em Moçambique, abordada por João Paulo Guerra quando, em 1966/1967, ali cumpre serviço militar ${ }^{12}$.

Na sua maioria, os artigos recenseados contêm imagens a preto e branco. Há artigos com apenas uma imagem a preto e branco (30\%), mas $40 \%$ têm quatro ou mais imagens. A maior profusão de imagens encontra-se nas reportagens que já referimos, feitas por funcionários do RCP em contexto de serviço militar. São fotografias que legendam construtivamente uma situação de guerra, quase sempre retratando os militares na chamada "acção psicossocial" junto das populações indígenas. Ainda no que respeita à componente visual, apenas uma capa se refere ao universo colonial, fazendo uma chamada para uma das reportagens de João Paulo Guerra em Moçambique.

Em seguida, desenvolvemos algumas linhas, do ponto de vista qualitativo, sobre o conteúdo de alguns artigos publicados na revista Antena sobre o universo colonial na década de 1960 e a abordagem que dele fazem.

12 Cf. ponto 4 deste artigo. 
4. Reportar em teatro de gUerRa: os JORnalistas que SÃo SOLdados

Em 1966 e 1967, a Antena oferece aos leitores um olhar in loco sobre a guerra colonial. Fernando Peres, o editor, aproveita a ida de profissionais do RCP para as "colónias" em serviço militar e pede-Ihes que escrevam sobre o que lhes parecer interessante ${ }^{13}$. Da estada de Macieira de Barros (noticiarista) e Óscar de Araújo (operador dos serviços técnicos) em Angola, em 1966, resultaram quatro artigos, genericamente intitulados "Nas fileiras de Angola". Em 1967 será o noticiarista João Paulo Guerra, que, estando em Moçambique, escreve dois artigos sobre "Uma guerra sem frente".

Estes artigos, que considerámos em termos operativos reportagens, são híbridos. Os artigos de Barros e Araújo são feitos com elementos de crónica e de reportagem. Os artigos de João Paulo Guerra são reportagens que também contemplam análise. Todos eles têm a indicação expressa de serem um "exclusivo" da revista. De todas as reportagens feitas em Angola e Moçambique, só uma, de João Paulo Guerra, foi chamada de capa.

A partir destes seis artigos, indagamos sobre a experiência de ser soldado nestes teatros de guerra, a visão dos "enviados" sobre as populações nativas, e que informações nos dão sobre a(s) guerra(s) em si.

\subsection{Em Angola}

Em 1966, Macieira de Barros está em Angola a cumprir serviço militar. Um dos artigos que envia para Portugal, a publicar na Antena, centra-se na descrição de uma acção psicossocial, nome dado àquela acção desenvolvida pelas forças militares que se destinava a influenciar as atitudes e o comportamento dos indivíduos em contexto de guerra subversiva. 0 objectivo era obter 0 apoio da população, desmoralizar e captar 0 inimigo, e fortalecer a moral das próprias forças. A acção psicossocial exercida sobre a população constituía um instrumento paralelo às armas convencionais. Procurava-se criar um ambiente favorável às tropas portuguesas, cativando os populares através da assistência sanitária, religiosa, educativa e económica ${ }^{14}$.

Barros integra uma coluna militar, algures em Angola. É no terreno que o repórter contacta com a população local e dá conta da interacção entre os soldados portugueses e os nativos. 0 soldado é visto pelo repórter como alguém altruísta e abnegado. As suas relações com os locais são afáveis, porque "contacta com as autoridades tradicionais e com as populações nativas, inteirando-se das suas dificuldades, dos seus problemas e das suas aspirações... sempre com uma palavra amiga ou a solução para o seu problema"15.

Por contraponto, Óscar Araújo reporta uma missão repressiva, de captura do inimigo. Aos soldados de Araújo falta a vertente humana e relacional. São, antes, elogiados como bem preparados e rotinados na sua missão. Junto do inimigo tanto

13 Foi o que aconteceu, pelo menos, com João Paulo Guerra, que, em entrevista, afirmou que Fernando Peres deve ter feito a mesma diligência junto dos colegas Macieira de Barros e Óscar de Araújo.

14 Incentivos/Propaganda. In: (http://www1.ci.uc.pt/cd25a/wikka.php?wakka=socguerr/\#incpro) (acedido em 11/06/2016).

15 Antena, n. ${ }^{0} 32,15 / 06 / 1966$, p.41. 
podem gerar medo ou alegria ${ }^{16}$. Cumprida a missão, para Araújo no rosto de cada soldado "brilha um sorriso de confiança e de satisfação da missão cumprida e dos resultados obtidos. ${ }^{17} \mathrm{Na}$ escrita do repórter, ir à guerra é um dever que garante amadurecimento físico e emocional. Araújo sintetiza as vantagens da guerra numa expressão: "Saiem [sic] homens feitos daqui!18"

No que respeita ao entendimento que fazem das populações nativas, ambos partilham a mesma visão paternalista. Macieira de Barros, por exemplo, descreve a chegada de uma patrulha a uma aldeia de uma forma gloriosa: "Hoje em dia é espectáculo de rotina assistir-se à entrada triunfal de uma patrulha militar numa aldeia nativa, com as crianças a rodearem as viaturas, saltando para o colo dos militares." ${ }^{19}$ Estas populações são apresentadas como carenciadas, dependentes dos "braços válidos dos soldados"20.

Nestes artigos nunca sabemos qual a localização ou data específica de permanência nos locais, muito provavelmente por imperativos de segurança. A guerra que sai destes artigos é uma guerra de vivos, na qual mortos e feridos não têm lugar. E é também uma guerra ganha: "poderemos dizer que, graças à acção eficaz das forças armadas, punhado de bravos guerreiros, movimentos desordenados não resultaram e cremos bem que nunca resultarão, enquanto esta determinação e este desejo de não largar o que é nosso se mantiverem inalteráveis, tanto em nós, militares, como em toda a população civil, também enorme deste enorme mas nobre sacrifício de continuar Portugal!?1"

Tanto Macieira de Barros como Óscar Araújo emitem opinião nos artigos que escrevem. Araújo, que não era jornalista mas técnico, é o mais enfático e prolixo em adjectivos quando descreve a sua experiência. Macieira de Barros gere melhor a fronteira entre 0 que pensa e 0 fim a que se destina 0 artigo. Talvez fruto da sua experiência como noticiarista, o seu texto é mais narrativo do que doutrinário.

\subsection{Em Moçambique}

João Paulo Guerra, noticiarista do RCP, é chamado a cumprir serviço militar em Moçambique em 1966. 0 chefe de redacção, sabendo-o de partida para Moçambique, pede-lhe para que escreva algo sobre a situação que encontrar.

A dada altura, João Paulo Guerra é integrado no serviço de Informações da 2. ${ }^{2}$ Repartição, onde se procura documentar sobre a guerra em curso e o que gravita em torno dela, o que será um dos elementos diferenciadores nas duas reportagens face às que vimos anteriormente. Ao estudo, o noticiarista alia a observação dos factos no terreno. É o caso do acompanhamento que faz de uma companhia de caçadores na deslocação entre Vila Cabral e Olivença. Antes de desenvolver 0 relato desta incursão militar, João Paulo Guerra faz uma declaração de intenções.

16 Antena, n. ${ }^{\circ} 42,15 / 11 / 1966$, p. 35

17 Idem.

18 Antena, n. ${ }^{0} 41,01 / 11 / 1966$, p.38.

19 Antena, n. ${ }^{0} 32,15 / 06 / 1966$, p. 41.

20 Idem.

21 Antena, n. ${ }^{\circ} 41,01 / 11 / 1966$, p.38. 
Afirma-se, simultaneamente, noticiarista e participante de uma operação militar, e compromete-se junto do leitor a cumprir valores que, embora não o diga desta forma, sustentam o jornalismo:

Tentarei dar aos leitores de Antena um aspecto concreto da guerra que se processa no Norte de Moçambique. Escolhi para tal esta operação, em que participei como alferes miliciano, atirador de infantaria e que tentei observar com a frieza e isenção de noticiarista. ${ }^{22}$

Objectividade, isenção e rigor dão o mote ao trabalho a que João Paulo Guerra se propõe. Por oposição aos repórteres de Angola, Guerra apresenta mapas, dá referências geográficas, e fornece dados quantitativos. Pela primeira vez, é referido 0 contexto mais vasto no qual se esgrimem os conflitos coloniais. Não é um combate isolado, nesta ou naquela "colónia", mas antes uma guerra mantida em três frentes ${ }^{23}$. 0 rigor que João Paulo Guerra procura na escrita, passa também pelo planeamento. Cinquenta anos depois, o repórter recorda como estruturou estes dois artigos:

Pensei, vou fazer uma coisa com algum cuidado. Fazer um artigo de enquadramento, que explicasse o movimento mundial de guerrilhas naquela altura, porque Moçambique não era um caso isolado. Um primeiro artigo teria, assim, uma base mais teórica. Só depois faria um artigo sobre a deslocação de uma companhia inteira de 150 homens, mais uma divisão de engenharia, onde citava o relatório do capitão da companhia. ${ }^{24}$

Nos artigos de Guerra o inimigo não é uma entidade difusa. São pessoas concretas, associadas a uma força política - a Frelimo -, e a um projecto de independentização ${ }^{25}$. Contrariando os outros registos paternalistas e de menorização do inimigo, João Paulo Guerra, especificamente no que respeita ao cenário de guerra moçambicano, considera que as forças do inimigo têm preparação técnica e beneficiam de apoio internacional ${ }^{26}$.

A visão que João Paulo Guerra transmite ao leitor relativamente aos soldados portugueses em Moçambique difere em muito da glória e valentia de que está eivado 0 discurso colonial estado-novista (Ribeiro, 2004: 117-151). Na escrita do repórter existem palavras que conferem um outro matiz à realidade de quem combate por Portugal neste território. "Nervosismo", "perigo", "medo", "angústia" e "exaustos"27 são termos que contrariam os ditames de uma glória construída. 0 soldado, analisado por este prisma, contraria o mito do heroísmo português, na exacta medida em que ganha espessura humana:

22 Antena, n. ${ }^{0} 66,01 / 12 / 1967$, p. 17.

23 Antena, n. ${ }^{\circ} 65,15 / 11 / 1967$, p. 25.

24 Entrevista dada por João Paulo Guerra à autora em 20 de Junho de 2016.

25 Antena, n. ${ }^{\circ} 65,15 / 11 / 1967$, p. 23.

26 Antena, n. ${ }^{\circ} 65,15 / 11 / 1967$, p. 24.

27 Antena, n. ${ }^{\circ} 66,01 / 12 / 1967$, pp. 17 e 19. 
No Norte de Moçambique, como em qualquer outro ponto do globo em que homens se batem com outros homens, há lugar para todos os sentimentos. Vive-se e consequentemente ama-se, sofre-se, espera-se, têm-se alegrias e tristezas, porque são homens que cá se encontram e é da condição humana amar, sofrer, ter esperança e ser alegre ou triste conforme as circunstâncias. No Norte de Moçambique encontram-se homens que, acima de tudo, sentem. ${ }^{28}$

Quando falámos com João Paulo Guerra, colocámos uma pergunta fundamental: com esta abordagem dos conflitos em Moçambique, como foi possível que estes artigos passassem no crivo da censura? Guerra explica-nos que enviou ambos os artigos, por correio, em Março de 1967. Porém, quando regressa de Moçambique, em Outubro, os artigos ainda não haviam sido publicados. 0 chefe de redacção diz- Ihe que as reportagens não passaram na censura. As duas tinham sido cortadas na totalidade, "talvez por conterem informações confidenciais sobre contingentes militares e localizações geográficas"29. Guerra recorre ao então Coronel Pedro Car-

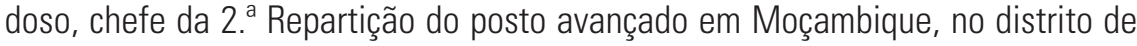
Nampula, com quem tinha trabalhado, e conta-Ihe da censura às duas reportagens. Só após esta conversa os artigos viriam a ser publicados na Antena, sem cortes, em Novembro do mesmo ano.

\section{As viagens presidenciais à Guiné e a Cabo Verde: onde a Guerra não é notícia}

Em 1968, Américo Tomás faz uma viagem a Guiné e a Cabo Verde a bordo do paquete "Funchal". Antes, já o Presidente da República (PR) se tinha deslocado a Angola (1963) e a Moçambique (1964), do mesmo modo que em 1970 fecharia o ciclo de visitas ao "Ultramar" com a ida a São Tomé e Príncipe.

A guerra colonial foi o pano de fundo e o motor destas visitas presidenciais. 0 objectivo era, como reflectem os diários e as crónicas das viagens de Américo Tomás ${ }^{30}$, forjar um ambiente de "sentimentos nacionais e de unidade e fidelidade das parcelas além-mar à Mãe Pátria"31, tanto para aplacar o descontentamento popular e reforçar a propaganda do regime, como para dar resposta às pressões externas.

0 cerco internacional era cada vez mais expressivo, com a $\mathrm{ONU}$ a contestar 0 regime e a guerra colonial, assim como a maioria dos países afro-asiáticos, vários países do Norte da Europa, o Brasil e até a Espanha de Franco (Rosas, 1998: 482483). 0 regime sabia-se "em hora particularmente grave para a Nação" 32 , mesmo quando proclamava que as viagens presidenciais eram um "triunfo nacional na

28 Antena, n. ${ }^{\circ} 66,01 / 12 / 1967$, pp. 19.

29 Entrevista dada por João Paulo Guerra à autora em 20 de Junho de 2016.

30 As viagens presidenciais foram quase sempre acompanhados de um livro descrevendo a viagem e de um álbum com as fotografias mais importantes, da responsabilidade da Agência Geral das Colónias, depois designada Agência Geral do Ultramar.

31 Diário da Viagem do Presidente Américo Thomaz a Moçambique e Ilha do Príncipe, 1965, p. 7

32 Idem. 
diversidade étnica e geográfica do Mundo Português." ${ }^{33}$ E defendia-se, escudando-se na incompreensão externa: "0 Mundo, que nos detracta e nos cobiça, menosprezando a nossa resistência moral, esse, decerto terá saído mais desiludido e menos convicto das suas possibilidades de êxito." ${ }^{34}$

No dia 28 de Janeiro de 1968, Américo Tomás inicia a sua terceira viagem a África. Durante um mês percorre, primeiro, uma Guiné em guerra, que o discurso oficial suaviza. 0 ónus do problema estaria nos "inimigos de Portugal", que diziam que a Guiné estava "ocupada pelos bandos terroristas em quatro quintos do território e onde - afirmavam eles - não se poderia dar um passo fora das cidades sem fortíssima escolta militar" ${ }^{\prime 35}$. Depois segue para o pacífico Cabo Verde, "a primeira experiência plurirracial dos Portugueses no Mundo, (...) as ilhas habitadas por um povo crioulo apaixonadamente português" ${ }^{\prime \prime}$.

Com Américo Tomás embarcou uma extensa comitiva, constituída por representantes do Estado, como o ministro do Ultramar, Silva Cunha, o secretário nacional da Informação, Moreira Baptista, o chefe da Casa Militar, Henrique Tenreiro, e vários jornalistas. Entre eles, Fialho de Oliveira (Diário de Notícias), Luís Rosa Duarte (O Século), Mário Rocha (Diário Popular), Afonso Serra (A Capital), e Joaquim Letria (Diário de Lisboa). No que respeita à rádio, esteve presente a EN e o RCP. Da equipa do RCP faziam parte Manuel Bravo, Jaime da Silva Pinto e Mário Paiva de Sousa. ${ }^{37}$

A Antena não deixa passar este "acontecimento de tão profundo significado nacional" ${ }^{\prime 38} \mathrm{e}$, em duas notícias breves, anuncia a ida deste grupo de profissionais do RCP para fazer a cobertura da viagem. 0 primeiro artigo ${ }^{39}$, escrito com a viagem em curso, apresenta a equipa que já referimos: Manuel Bravo, locutor e noticiarista ${ }^{40}$; Jaime Silva Pinto, assistente de produção; e Mário Paiva, técnico. Elogiam-se as competências dos profissionais e as reportagens já realizadas, "onde se evidenciam o carinho e a vibração das populações nativas perante 0 mais alto magistrado da Nação." ${ }^{" 11}$ A "emoldurar" a notícia está uma fotografia dos três, tirada antes da partida, frente ao paquete "Funchal".

No segundo artigo ${ }^{42}$, escrito finda a viagem, é feito um breve balanço da viagem presidencial e da cobertura do acontecimento pelo RCP. Duas imagens fazem a legenda construtiva do texto. Numa, Manuel Bravo entrevista Henrique Tenreiro; noutra o entrevistado é Moreira Baptista e quem lhe estende o microfone é Sil-

33 Idem.

34 Idem.

35 Crónica da Viagem do Presidente Américo Thomaz à Guiné e Cabo Verde, 1968, p. 9.

36 Idem.

37 Idem, pp. 11-12.

38 Antena, n. ${ }^{0} 71,15 / 02 / 1968$, p. 20.

39 Idem.

40 Nesta notícia, Manuel Bravo é apenas referido como locutor, mas sabemos que ele pertencia também à equipa de noticiários de Luís Filipe Costa.

41 Antena, n. ${ }^{0} 71,15 / 02 / 1968$, p. 20.

42 Antena, n. ${ }^{0} 72,01 / 03 / 1968$, p. 14. 
va Pinto. Com microfones bem identificados, e entrevistados e repórteres bem visíveis, estas fotografias constituem a prova para os leitores da presença do RCP na viagem presidencial, e testemunham os "exclusivos" do RCP com estas figuras destacadas da entourage de Tomás. A cobertura terá sido transmitida diariamente, "ora com reportagens plena de interesse e oportunidade, ora em crónicas de perfeita actualidade." ${ }^{43}$ Para a Antena, 0 trabalho aturado dos profissionais do RCP na cobertura deste acto oficial é, uma vez mais, representativo do lema da emissora: "Sempre no Ar! Sempre consigo".

Destas notícias breves resulta uma cobertura jornalística colada à agenda da viagem de Estado e à sua agenda ideológica, fixada nos actos oficias dos visitantes e desligada da realidade dos povos visitados. Esta ideia é corroborada pela análise sumária dos registos sonoros do arquivo do RCP que dizem respeito à viagem de $1968^{44}$. 0 material sonoro testemunha a viagem desde 30 de Janeiro, data da primeira gravação existente, até ao dia 11 de Fevereiro, dez dias antes da entrada da comitiva em Lisboa. Os registos áudio do RCP constituem, essencialmente, uma colecção de discursos oficiais, entre os quais: o discurso de Silva Cunha, a bordo do paquete "Funchal" (30/1); declarações de Henrique Tenreiro, a bordo do paquete, sobre a vocação marítima portuguesa (30/1); declarações de Moreira Baptista, a bordo do paquete, de elogio à comunicação social (01/02); discurso de boas vindas ao Presidente da República pelo presidente da Câmara Municipal de Bissau, e respectivo discurso de agradecimento de Américo Tomás (01/02); discurso na recepção da Câmara de Bissau pelo Governador Geral da Guiné, e respectivo discurso de agradecimento de Américo Tomás (01/02); discurso de boas vindas ao PR pelo presidente da Câmara Municipal da Praia, e respectivo discurso de agradecimento de Américo Tomás (09/02); e o discurso de boas vindas pelo Governador Geral de Cabo Verde, e respectivo discurso de agradecimento de Américo Tomás (09/02)45.

As reportagens e crónicas feitas pela equipa do RCP durante esta viagem não parecem, assim, ultrapassar os limites rígidos e seguros da ressonância dos poderes do regime. 0 "interesse", "oportunidade" e "actualidade" que as notícias exaltam não vão além dos limites do paquete "Funchal" e das cerimónias oficias, com os seus discursos previsíveis e circulares. E muito menos são pretexto experimentado para relatar, pela observação e pelo contacto directo, a realidade dos povos africanos ou o conflito armado em curso.

\section{José Chimunga: 0 "pequeno herói que veio do Bié"}

Entre Agosto e Outubro de 1968, a Antena acompanha o percurso de José Chimunga, a criança de 12 anos eleita representante de Portugal na Operação Plus UI-

43 Idem.

44 Embora não seja objecto deste estudo a análise dos registos sonoros do fundo documental do RCP, uma vez que o foco é a revista Antena, resolvemos, numa audição breve de reconhecimento, cruzar os dados da revista com o material que, do ponto de vista sonoro, atesta o trabalho da equipa jornalística do RCP que cobriu esta viagem presidencial.

45 Arquivo Audiovisual da RTP, Fundo RCP (cf. referências completas na bibliografia final). Ao todo são 19 os registos sonoros encontrados sobre a viagem de Américo Tomás de 1968. 
tra, juntamente com crianças de Espanha, Itália, Alemanha, Jugoslávia e Bélgica. Esta "operação", em curso desde 1963, com origem no programa radiofónico com 0 mesmo nome, da autoria de Joaquin Peláez, locutor na Rádio Madrid, era uma iniciativa da Sociedade Espanhola de Radiodifusão e da transportadora aérea Iberia, sendo coordenada em Portugal pelo RCP. 0 objectivo era construir uma "galeria dos pequenos heróis", feita de crianças consideradas exemplares, a quem eram atribuídos "feitos heróicos".

José Chimunga, natural de Angola, da aldeia de Chicundo, província do Bié, terá salvado das garras de um leão, com um machado, dois homens em risco. A narrativa da revista traça uma mitificação do acto heróico de José. Não bastava a sua descrição objectiva. É-Ihe acrescentado o ritmo e o tom vívido do acontecimento, não presenciado pelo jornalista, que 0 amplia e cativa o leitor:

Uma flecha partiu. Um fio de sangue riscou-lhe a pelagem. A dor e 0 fracasso exasperaram o faminto leão que, num relance, avistou 0 atirador e, dum salto, derrubou-o e prendeu-o nas garras. (...) o pequeno Chimunga, empunhando um machado como única arma, correu sobre o leão e destemidamente, sem querer pensar no perigo de morte que também o ameaçava, vibrou no lombo da fera golpes tão fortes que Ihe originaram diversas fracturas da coluna vertebral." "46

Ao contrário de Regina dos Anjos, Nelson José ou Manuel Augusto, portugueses da "metrópole" que anteriormente tinham participado nesta iniciativa", a Operação Plus Ultra no ano de 1968 terá uma extensa cobertura. Em vez das poucas páginas que foram dedicadas aos anteriores participantes, José Chimunga convoca um interesse, do qual resultarão quatro artigos em quatro revistas, num total de sete páginas.

Para a revista do RCP, José Chimunga é o "rapazinho de Angola"48, o "pequeno herói", 0 "herói de Chicundo"49. Chimunga é retratado como a criança exemplar que honra Portugal, a quem são atribuídas qualidades físicas e morais de excepção, como a valentia, a coragem, a simpatia ${ }^{50}$, o sentimento de amor ao próximo $^{51}$, a simplicidade e ausência de vaidade ${ }^{52}, 0$ espirito altruísta e a mística de herói53. A criança do Bié é, enfim, "um belo exemplo de valor humano" 54 .

46 Antena, n. ${ }^{\circ} 83,15 / 08 / 1968$, p.7.

47 Antena, n. ${ }^{\circ} 83,15 / 08 / 1968$, p.6.

48 Idem.

49 Antena, n. ${ }^{0} 84,1 / 9 / 1968$, p.8.

50 Antena, n. ${ }^{\circ} 84,1 / 9 / 1968$, p.9.

51 Antena, n. ${ }^{\circ} 83,15 / 08 / 1968$, p.6.

52 Antena, n. ${ }^{\circ} 84,1 / 9 / 1968$, p.8.

53 Idem.

54 Antena, n. ${ }^{\circ} 83,15 / 08 / 1968$, p.6. 


\section{OPERAÇÃO PLUS ULTRA/68}
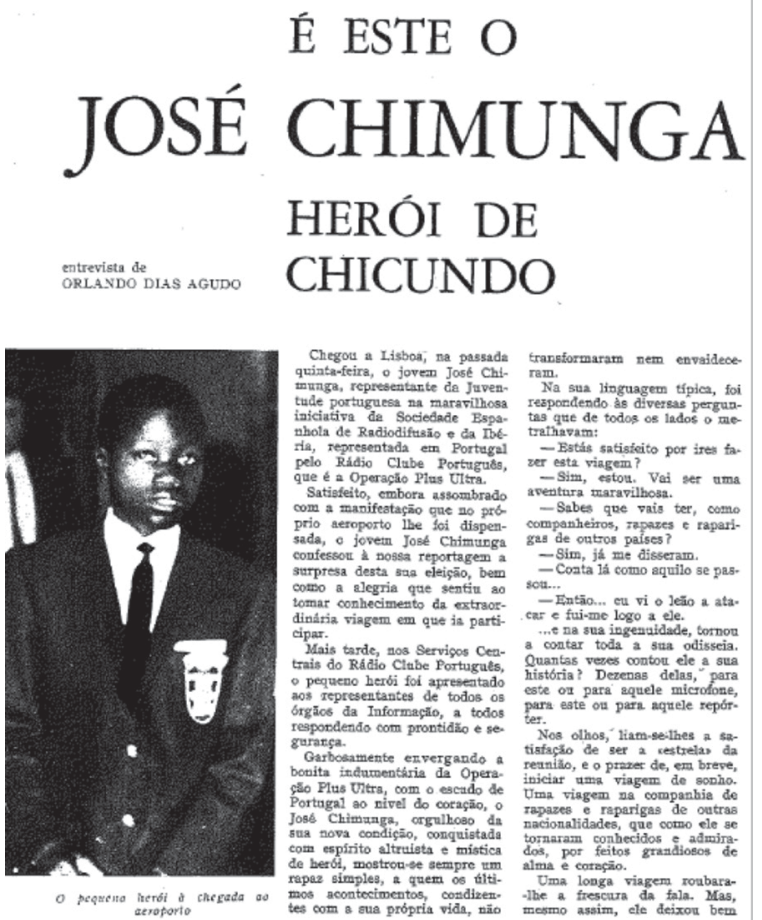

0 valor facial do "herói de Chicundo" é tão ou mais importante quanto a sua figura e a narrativa que a envolve se transformam em apoio e legitimação da condição colonial de Portugal. Mais do que intrínsecas, as qualidades de Chimunga são apresentadas como fruto da unidade pluricontinental e plurirracial defendidas pelo regime. Na Antena, o jornalista promove a ideologia colonial do Estado Novo e participa dela, afirmando que o respeito pelo jovem angolano assenta na certeza de ver continuadas, "em terras angolanas, a valentia e a coragem que sempre sublinharam 0 sangue português" 55 . Não é português quem pode, mas quem recebe "a graça" de pertencer a essa osmose, filha das políticas coloniais do Portugal em ditadura. Chimunga é o "negrito portugués (...) traído desde las selvas de Angola"56, como refere o diário espanhol $A B C$ Sevilha. É uma espécie de figura redentora, generosamente trazida para a Europa, longe das "selvas" africanas, cuja proveniência e cor da pele são indispensáveis à máquina da propaganda.

55 Idem.

56 ABC Sevilla, 12/09/1968. 
Ao longo de cerca de um mês, Chimunga faz a "viagem de sonho"57, prémio da sua participação na Operação Plus Ultra de 1968, juntamente com as restantes crianças. Chimunga parte para Madrid no dia 30 de Agosto, segue para Roma onde é recebido pelo Papa Paulo VI, e regressa a Espanha para visitar Barcelona, Palma de Maiorca, Valência, Sevilha, Gerez, Cadiz, Casablanca, Tenerife e Las Palmas e, novamente, Madrid, onde é recebido por Franco. 0 périplo termina com o regresso a Lisboa, e o posterior encontro com Américo Tomás ${ }^{58}$, no princípio de Outubro.

É interessante analisar os excertos de duas entrevistas ao "pequeno herói", contidas nos artigos. À chegada a Lisboa, Chimunga é recebido por alguns órgãos de comunicação social. 0 repórter da Antena afirma que Chimunga se expressa na sua "linguagem típica", o que remete para uma ideia de pitoresco, associada aos povos colonizados. No entanto, ambas as entrevistas apresentam sinais, não de uma "linguagem típica" 59 , mas de um discurso formatado e alinhado com o ideário colonial da época. Por exemplo, quando regressado de Espanha, José Chimunga, ter-se-á dirigido aos jornalistas, resoluto:

Queria pedir-lhe o favor de mandar dizer, à minha família, e ao senhor Governador do Distrito do Bié, que estou de saúde, gostei imenso desta viagem. Todos me trataram bem, e espero o momento de novamente me poder encontrar com eles, para os abraçar fortemente. Isto, realmente é muito bonito, mas, para falar francamente, as saudades da minha terra, e dos meus amigos, já são muitas... ${ }^{60}$

É notório que este discurso não é consentâneo com a idade nem com o contexto sócio-cultural de Chimunga. Do vocabulário utilizado e do conteúdo das respostas, fica-nos a ideia de que o texto, até nas entrevistas, é contruído com a intensão de colorir e ancorar a realidade colonial. Em detrimento da factualidade, assiste-se ao desvirtuar e à manipulação da mensagem; ao reforço da ideia de harmonia entre os povos de aquém e além-mar; ao exacerbar dos mitos do multirracialismo e da missão "civilizadora" dos portugueses (Torgal, 2009: 493-497); e à afirmação do carácter dócil do "outro". É, em síntese, a propaganda a cumprir a sua missão, particularmente urgente em tempo de guerra contra os movimentos pela independência de Angola, Moçambique e Guiné.

Este prémio que enquadrou o "pequeno-herói" do Bié, da responsabilidade do RCP em Portugal, instrumentalizou-o em função do quadro ideológico do regime. Pela primeira vez uma criança vinda das "colónias" fez parte da Operação Plus Ultra. $A$ Antena, veículo escrito do RCP, acompanha a par e passo os acontecimentos, ilustra proficuamente os artigos com fotografias de Chimunga, nos mais variados momentos da sua estada "feliz" na Europa. É evidente a utilização da criança angolana pelo RCP como bandeira ideológica do regime e compromisso da emissora com ele, num contexto de guerra em Angola que nunca é mencionado. Da mesma maneira que não terá sido inócua a participação e vitória, no ano anterior, do angolano Eduardo Nascimento no Festival RTP da Canção, com a canção ironicamente intitulada "0 vento mudou".

57 Antena, n. ${ }^{\circ} 85,15 / 09 / 1968$, p.20.

58 Antena, n. ${ }^{\circ} 84,1 / 9 / 1968$, p.9.

59 Antena, n. ${ }^{\circ} 84,1 / 9 / 1968$, p.8.

60 Antena, n. ${ }^{\circ} 86,1 / 10 / 1968$, p.18. 
7. Notas Finais: A guerra? Qual guerra?

A leitura que a revista Antena, "braço escrito" do RCP, oferece (ou não) sobre a forma como o universo colonial português, e designadamente a guerra em África, são representados tem de ser filtrada por alguns constrangimentos internos e externos.

Primeiro que tudo, a lógica de propaganda da revista ao serviço da estação de rádio sua proprietária, mais interessada em usá-la como sua montra promocional e como registo leve da vida das "estrelas" - que certamente era factor capitalizador de leitores, sobretudo do sexo feminino -, do que como objecto de debate alargado sobre temas que exigem outra profundidade.

E depois, o contexto histórico e o edifício ideológico do país, absolutamente adversos a que um tema desta natureza fosse tratado. Num país despolitizado e em regime de censura, não há dinâmicas informativas que tornem ágil e possível o conhecimento da realidade. E, não nos esqueçamos, o RCP de vanguarda em termos técnicos e de estética radiofónica, o RCP que sempre pugnou pela independência e pela "profissionalização", é o mesmo que Botelho Moniz criou em 1931, umbilicalmente ligado ao salazarismo, e que se colocou ao serviço de Franco. É essa a matriz político-ideológica do RCP.

No entanto, pelos artigos da Antena, mesmo que sob a égide da autopromoção da estação e da ingenuidade dos temas e das narrativas, encontramos fragmentos da "realidade" colonial, a partir da qual os leitores podem construir uma realidade inventada.

Vimos como o RCP, através da revista Antena, tomou a iniciativa de pedir a João Paulo Guerra, Macieira de Barros e Óscar Araújo que, uma vez a cumprirem o serviço militar nas "colónias", aproveitassem para escrever alguns artigos sobre o que encontraram na África em guerra. É a guerra o motivo que leva estes homens a escrever, mas os "retratos" que enviam pelo correio, à excepção das reportagens de João Paulo Guerra, mais precisas e desapaixonadas, insistem na visão patriótica, nacionalista e paternalista sobre os soldados e as populações nativas.

É também a guerra a causa da viagem presidencial à Guiné e a Cabo Verde. Mas, nas notícias da Antena, a guerra não tem lugar. Não se vislumbra na descrição da viagem, assim como nada sabemos sobre os territórios visitados. Do ponto de vista do jornalismo radiofónico do RCP, só nos artigos da viagem este é referido. Vemos a promoção que é feita da equipa que acompanha Américo Tomás, através de fotografias, e sabemos que os jornalistas captaram os discursos proferidos ao longo da viagem. 0 que nos obriga a colocar uma questão: se 0 jornalismo radiofónico vive as transformações que referimos, estas foram essencialmente ao nível da forma, nos aspectos técnico e da linguagem, ou estenderam-se verdadeiramente ao conteúdo?

No caso de Chimunga, é também a guerra, indirectamente, que mobiliza a escrita dos artigos cândidos que exaltam as virtudes da criança-herói. Porque é esse exacerbar da pureza e da valentia de Chimunga, e da "viagem de sonho" proporcionada, que gera um discurso que eclipsa o dramatismo da guerra, a situação das forças em presença, e a realidade vivida, das sanzalas no mato à Baía de Luanda. É a guerra que faz com que a revista construa um país de ficção, onde a harmonia de aquém e de além-mar é lei.

Exceptuando as reportagens de João Paulo Guerra em Moçambique, a representação que a Antena nos oferece do mundo colonial português é a de um lugar de paz, mesmo quando a guerra é referida em alguns artigos. É um espaço imaginado dócil, virginal, único, e subserviente, mas também alegre e pitoresco. Na Antena, como noutras publicações, a guerra colonial nunca existiu. 


\section{FONTES}

\subsection{Periódicos}

Antena (1965-1968)

\subsection{Arquivo Audiovisual da RTP}

AHD9122 - Visita do Presidente da República à Guiné e a Cabo Verde

\subsection{Entrevistas}

Adelino Gomes (19/06/2015);

João Paulo Guerra (07/05/2014; 20/06/2016)

Luís Filipe Costa (20/10/2014).

\section{LiVROS E ARTIGOS}

Baptista, Carla (2012). A Política nos Jornais Portugueses. Do Século XIX ao Marcelismo. Lisboa: Escritório Editora.

Bonixe, Luís (2009). A Informação Radiofónica: Rotinas e Valores-notícia da Reprodução da Realidade na Rádio Portuguesa. A Internet como Cenário Emergente. Dissertação de doutoramento apresentada na FCSH/ UNL.

Bonixe, Luís (2012). A Informação Radiofónica. Rotinas e Valores-notícia da Reprodução da Realidade na Rádio Portuguesa. Lisboa: Livros Horizonte.

Cabrera, Ana (2006). Marcello Caetano: Poder e Imprensa. Lisboa: Livros Horizonte.

Correia, Fernando, \& Baptista, Carla (2007). Jornalistas. Do Ofício à Profissão. Lisboa: Caminho.

Cristo, Dina (2005). A Rádio em Portugal e o Declínio do Regime de Salazar e Caetano (19581974). Coimbra: MinervaCoimbra.

Crónica da Viagem do Presidente Américo Thomaz à Guiné e Cabo Verde. Agência Geral do Ultramar, 1968. In: (http://memoria-africa.ua.pt/Library/VisitasPresidenciais.aspx) (acedido 11/06/2016).

Diário da Viagem do Presidente Américo Thomaz a Moçambique e Ilha do Príncipe. Agência Geral do Ultramar, 1965. In: (http://memoria-africa.ua.pt/Library/VisitasPresidenciais. aspx) (acedido 11/06/2016).

Fontan, Eugenio. "Plus Ultra" - Una obra de union entre los hombres. ABC Sevilla. 12/09/1968. Incentivos/Propaganda. In: (http://www1.ci.uc.pt/cd25a/wikka.php?wakka=socguerr/\#incpro) (acedido em 11/06/2016)

Maia, José Matos (2009). A Telefonia. Memórias da Rádio. Lisboa: Âncora Editora.

Ribeiro, Margarida Calafate (2004). Uma História de Regressos. Império, Guerra Colonial e Pós-colonialismo. Porto: Edições Afrontamento.

Rosas, Fernando (1998). História de Portugal, vol 7 - Estado Novo, dir. José Mattoso. Lisboa: Estampa. 
Santos, Rogério (2012). A rádio portuguesa na década de 1960. A revista Antena (19651968) e a promoção da rádio. In: Ferin, Isabel et al (org.) Pesquisa em Media e Jornalismo. Covilhã: Labcom.

Santos, Rogério (2014). A Rádio em Portugal. "'Sempre no Ar, Sempre Consigo" (19411968). Lisboa: Colibri.

Torres, Sílvia (org.) (2016). O Jornalismo Português e a Guerra Colonial. Lisboa: Guerra e Paz. Torgal, Luís Reis (2009). Estados Novos, Estado Novo. Ensaios de História Política e Cultural, vol. 1. Coimbra: Imprensa da Universidade de Coimbra. 